\title{
Design of New Carbon-Phenolic Ablators: Manufacturing, Plasma Wind Tunnel Tests and Finite Element Model Rebuilding
}

\author{
L. Paglia ${ }^{1}$ (D) - V. Genova ${ }^{1} \cdot$ J. Tirillò ${ }^{1} \cdot$ C. Bartuli ${ }^{1} \cdot$ A. Simone ${ }^{2} \cdot$ G. Pulci ${ }^{1} \cdot$ F. Marra ${ }^{1}$
}

Received: 30 October 2020 / Accepted: 7 June 2021 / Published online: 30 July 2021

(c) The Author(s) 2021

\begin{abstract}
Ablative materials represent a widespread solution for shielding space vehicles from overheating during a reentry phase in atmosphere where the high heating fluxes and the consequent high temperatures cannot be compatible with the vehicle structure and with the safety of the payload and/or the crew. In this work, two different kinds of carbon-phenolic ablators with a density of $0.3 \mathrm{~g} / \mathrm{cm}^{3}$ were manufactured and their mechanical and thermal properties were experimentally evaluated. The thermal protection performances of the developed ablators were assessed in a hypersonic plasma wind tunnel facility, setting representative enthalpy and heat flux conditions $\left(6\right.$ and $\left.13 \mathrm{MW} / \mathrm{m}^{2}\right)$, consistent with atmospheric reentry missions from high energy orbits. Data of the experimental tests were compared with the results obtained by a finite element model built up for these materials with the commercial software SAMCEF Amaryllis. All results enlighten the good performances of the ablators under severe heat flux conditions and outline their operating limits.
\end{abstract}

Keywords Carbon-phenolic ablative materials · Plasma wind tunnel test · Finite element analysis $\cdot$ Specific heat $\cdot$ Bending test
Abbreviations
A Frequency factor
$c_{p} \quad$ Specific heat
$E_{a} \quad$ Activation energy
$H_{p} \quad$ Pyrolysis enthalpy
$K_{p} \quad$ Darcy constant
$n$ Order of reaction
$p \quad$ Pressure
$R \quad$ Universal gas constant
$T$ Temperature

L. Paglia

laura.paglia@uniroma1.it

1 Department of Chemical Engineering, Materials, Environment, INSTM Reference Laboratory for Engineering of Surface Treatments Via Eudossiana 18, Sapienza University of Rome, 00184 Rome, Italy

2 Thales Alenia Space Italia, S.da Antica Di Collegno, 253 -10146 Turin, Italy 


$\begin{array}{ll}\alpha & \text { Thermal diffusivity } \\ \lambda & \text { Thermal conductivity } \\ \check{\lambda} & \text { Blowing correction factor } \\ \rho & \text { Density } \\ \rho_{v} & \text { Virgin material density } \\ \rho_{c} & \text { Char material density }\end{array}$

\section{Introduction}

The thermal protection system (TPS) for an atmospheric reentry vehicle represents one of the most challenging components in its overall design: the TPS has to guarantee the safety and the integrity of the payload in harsh thermal and mechanical conditions [1-4]. According to the kind of space mission, a lifting or a ballistic reentry can be selected as reentry strategy. This choice influences the reentry velocity and the heat flux generated by the friction with the atmosphere: for a lifting reentry the velocity and the heat flux are lower, thus a passive thermal protection system consisting of ceramic tiles can provide suitable performances; for a ballistic reentry, characterized by higher velocity and heat flux, ablative materials represent the best solution in order to guarantee an appropriate dissipation of heat [5-8].This peculiar thermal protection system is adequate for reentry in Earth or other planet atmospheres, but the different atmospheric composition can influence the performance of the material $[9,10]$. Ablative materials can be classified as semi-active protection systems because they are not simple insulating materials (passive protection systems) and, at the same time, they do not use a refrigerating fluid (active protection systems) $[11,12]$. They can be divided into two subcategories: charring and non-charring ablators. Carbon/Carbon $(\mathrm{C} / \mathrm{C})$ ablative materials are well known non-charring ablators which are often employed in the nozzles of rockets [13]. Charring ablative materials consist of an organic resin and one or more reinforcement phases and they guarantee an efficient heat removal thanks to several mechanisms: for phenolic resins, when temperature reaches about $300{ }^{\circ} \mathrm{C}$, the endothermic pyrolysis reaction takes place guaranteeing energy absorption [14-17]; pyrolysis gasses are produced during the reaction and they absorb part of the heat by warming up themselves and, because of a pressure gradient, they flow in the boundary layer forming a barrier against convective heat exchange, this phenomenon is called blockage effect [2,18-20]. An ablative thermal protection system needs to satisfy different requirements: i) it has to protect the structure of the reentry vehicle and the payload from overheating; ii) the total required mass need to be as low as possible; iii) the recession of the shield has to be controlled in order to have predictable variations of the mass and shape of the vehicle [21].

A class of ablative materials denominated Light-weight Ceramic Ablators (LCA) has been largely employed in space missions because of their low density and high efficiency [22-24]. In particular, the Phenolic Impregnated Carbon Ablator (PICA) designed by NASA [25] was successfully employed as thermal shield of the Mars Science Laboratory for the delivering of Curiosity rover on Mars in 2012 [21] and it was selected also for the thermal protection of the Dragon Space X manned capsule [26, 27]. In order to obtain carbon-phenolic ablators with improved performances the manufacturing strategy, the choice of the solvent employed, the ratio between resin and solvent, the structure of the carbon felt and the nature of the phenolic resin have to be selected very carefully [14]. The characteristics of a thermal protection system (TPS) need to be well described in order to 
select the right system for a specific mission, and significant ground tests can be carried out in plasma wind tunnel (PWT) facilities, where the heat flux conditions encountered during a real reentry trajectory can be reproduced [28-31]. Data collected during a PWT test can be implemented in a FE model, in order to rebuild the performances of the tested ablative materials and create a numerical tool for the TPS design able to reduce the number of the required experimental tests performed in plasma wind tunnel facilities [32,33]. Considering all the complex mechanisms occurring during the heating of an ablative material, the required inputs for a finite element model (FEM) are numerous and concern virgin material, charred material and also pyrolysis gas.

The Laboratory of Materials and Surface Engineering of Sapienza University of Rome has worked on carbon-phenolic ablative materials since 2009. Several low density ablators were developed and optimized by varying raw materials, density, manufacturing strategy $[15,18,34]$ with a special effort for a complete characterization of mechanical and thermal properties [16], thermochemical and kinetics parameters [15, 34]. Some ablators were manufactured enriching the polymeric matrix with ceramic nano-particles of $\mathrm{Al}_{2} \mathrm{O}_{3}$ and $\mathrm{ZrO}_{2}[15,18]$. An oxyacetylene flame torch system was designed and set up in order to provide a useful screening of the ablative material potentialities [16, 23, 34]. The data collected were used for FEM simulations [14] and one of the first prototype was also tested in a plasma wind tunnel, Scirocco, CIRA (Italian Center of Aerospace Research) [14].

This research activity, in collaboration with Thales Alenia Space Italy, has the aim to optimize a carbon-phenolic ablator able to bear Earth atmospheric reentry from high energy orbits [7]. During previous research activities, another carbon-phenolic ablator was manufactured with a density of $0.5 \mathrm{~g} / \mathrm{cm}^{3}$ and tested in a plasma wind tunnel facility with a heat flux of $2.4 \mathrm{MW} / \mathrm{m}^{2}$ [14]. This work represents the attempt to improve that material, thus the manufacturing process was modified to obtain a lower density of $0.3 \mathrm{~g} / \mathrm{cm}^{3}$ and it was tested at 6 and $13 \mathrm{MW} / \mathrm{m}^{2}$ which are fluxes comparable with a reentry from Moon or from an interplanetary exploration (high energy orbit) [7, 35].

Two different kinds of carbon-phenolic ablative materials were manufactured with different carbon felts and their performances were tested in a Plasma Wind Tunnel (PWT) in particular in the L3 facility of DLR, Cologne (German Aerospace Center). The data collected during the exposure of the proposed ablators were employed for a rebuild of the test by a commercial Finite Element Method (FEM) software (SAMCEF Amaryllis) able to deal with recession and pyrolysis phenomena [36]. The FE model was built by considering both the measured properties of the manufactured materials and an open source database called TACOT (Theoretical Ablative Composite for Open Testing), that is a theoretical properties model of a carbon-phenolic ablative material [37].

\section{Materials and Methods}

\subsection{Manufacturing Method and Machining}

Two different kinds of carbon-phenolic ablative materials were manufactured with a commercial resol phenolic resin (Durite SC-1008, Hexion Chemicals) and two different carbon felts provided by SGL Carbon (RFA and MFA). The carbon felts distinguish for the length and the distribution of the carbon fibers: RFA Sigratherm is characterized by long fibers distributed on preferential planes and it consists of several layers of about $0.7 \mathrm{~mm}$ bound together with a carbonaceous binder, while MFA Sigratherm has long fibers (with 
a lower length compared to RFA's ones according to supplier information) with a random distribution. They both consist of graphite fibers and a carbonaceous binder, residual from the pyrolysis of a phenolic resin. In order to guarantee the desired final density of the samples $\left(0.3 \mathrm{~g} / \mathrm{cm}^{3}\right)$, the resin was diluted with a solvent (1-propanol) in a suitable proportion according to a yield curve calculated in a previous work [14]. In order to manufacture the ablative materials, the carbon felt samples were completely submerged into the solution of resin and solvent for 10 min which is a period of time sufficient to allow for a complete infiltration of the solution. Then the felt was removed from the solution and put inside a furnace where a selected cure cycle (optimized in a previous work [14]) assures the complete polymerization of the phenolic resin. In order to obtain samples with a suitable geometry for the test in the DLR facility, cubic samples with a side of $5 \mathrm{~cm}$ were manufactured and then machined by means of a milling process performed by a computer numerical controlled machine. The geometry and the machined samples are shown in Fig. 1. Samples manufactured with RFA carbon felt will be denominated RF, while samples manufactured with MFA carbon felt will be denominated MF.

\subsection{Thermal and Mechanical Properties Evaluation}

Three samples for each kind of material were tested by the Thermophysical Properties Section of the NETZSCH Applications Laboratory for the evaluation of the specific heat, thermal diffusivity and room-temperature bulk density. According to Eq. (1) these parameters were used to compute the thermal conductivity of the RF and MF ablative materials.

$$
\lambda(T)=\rho \cdot c_{p}(T) \cdot \alpha(T)
$$

$\lambda(T)$ is the thermal conductivity, $\rho$ is the density of the material, $c_{p}(T)$ is the specific heat and $\alpha(T)$ is the thermal diffusivity [38]. The thermal diffusivity was measured using a NETZSCH model 427 laser flash diffusivity apparatus. The unit used in this work was equipped with a high-temperature, water-cooled furnace capable of operation from 25 to $2000{ }^{\circ} \mathrm{C}$. The sample chamber is isolated from the graphite heating element by a protective tube allowing samples to be tested under vacuum or in an oxidizing, reducing or inert atmosphere. The temperature rise on the back face of the sample is measured using an

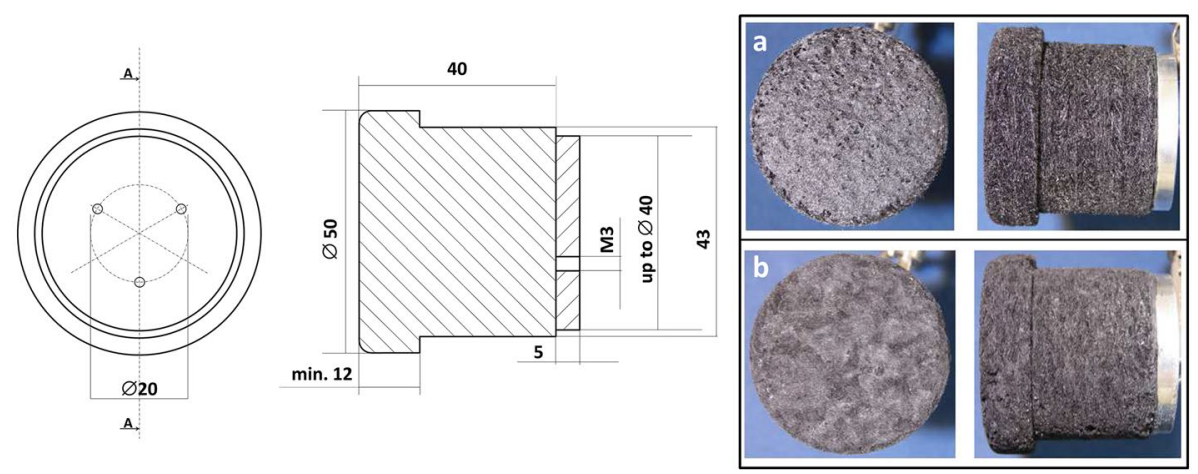

Fig. 1 Geometry of the samples and ablative material samples after machining and ready to be tested: a) ablative material manufactured with RFA Sigratherm (RF); b) ablative material manufactured with MFA Sigratherm (MF) 
In-Sb detector. The LFA 427 operates in accordance with national and international standards such as ASTM E-1461, DIN 30,905 und DIN EN 821 [39]. The thermal diffusivity measurements were conducted under vacuum between RT and $1950{ }^{\circ} \mathrm{C}$ with a sample holder with a diameter of $12.6 \mathrm{~mm}$. Each sample (cylindrical samples were prepared with a diameter of $12.5 \mathrm{~mm}$ and a thickness of $2.6 \mathrm{~mm}$ ) was coated with graphite on the front and back surfaces in order to increase absorption of the flash light on the samples' front surface and to increase the emissivity on the samples' back surface.

The specific heat measurements were conducted using a NETZSCH model DSC 404 $\mathrm{C}$ Pegasus differential scanning calorimeter capable of operation from 25 to $1500{ }^{\circ} \mathrm{C}$. The system is vacuum-tight, and therefore samples can be tested under pure inert, reducing or oxidizing atmospheres, as well as under vacuum. The measurements were carried out in a dynamic argon atmosphere (gas flow rate: $50 \mathrm{ml} / \mathrm{min}$ ). The system was equipped with a temperature-calibrated DSC-cp type S sensor. Platinum/Alumina crucibles with lids were employed for the tests. Each sample was heated between room temperature and $1400{ }^{\circ} \mathrm{C}$ at a heating rate of $20{ }^{\circ} \mathrm{C} / \mathrm{min}$. In order to obtain reliable results [40] the bulk samples were reduced to powder with an agata mortar, then the powders were well mixed and divided with the quartering method until obtaining the desired quantity for the test (about $40 \mathrm{mg}$ ).

Mechanical tests were conducted on 5 samples for each kind of material by a ZwickRoell Z10 machine equipped with a load cell of $1 \mathrm{kN}$. Four points bending tests were carried out at $2 \mathrm{~mm} / \mathrm{min}$ according to the ASTM standard for polymer matrix composite materials [41], thus samples with dimensions of $125 \mathrm{~mm} \times 10 \mathrm{~mm} \times 12 \mathrm{~mm}$ were manufactured and equipped with a strain gauge for the measure of the deformation during the test, as shown in Fig. 2. These experimental tests provided information about the Young's modulus and the flexural strength of the as-manufactured ablative materials.

\subsection{DLR Facility}

All PWT tests were carried out at DLR (German Aerospace Center, Cologne) in the L3K facility, one of the two test legs of DLR's arc heated facility LBK. L3K uses a segmented arc heater with a maximum electrical power of $6 \mathrm{MW}$ able to increase the enthalpy content of the working gas. Hypersonic free stream velocities are provided by a convergentdivergent nozzle which can work with different throat and nozzle exit diameters: the throat diameters can vary from 14 to $29 \mathrm{~mm}$ while nozzle exit diameters of $50 \mathrm{~mm}, 100 \mathrm{~mm}$, $200 \mathrm{~mm}, 300 \mathrm{~mm}$ are available. For this work a setup with a $29 \mathrm{~mm}$ nozzle throat and a $50 \mathrm{~mm}$ nozzle exit was selected and air was used as the working gas [42-44]. Samples manufactured with RFA and MFA Sigratherm carbon felt were tested at two different heat fluxes: $6.1 \mathrm{MW} / \mathrm{m}^{2}$ and $13 \mathrm{MW} / \mathrm{m}^{2}$. The selected testing time were $24.0 \mathrm{~s}$ and $30.0 \mathrm{~s}$ for the lower heat flux and $12 \mathrm{~s}$ for the higher heat flux. Similar parameters were selected also for

Fig. 2 Bending test sample equipped with a strain gauge

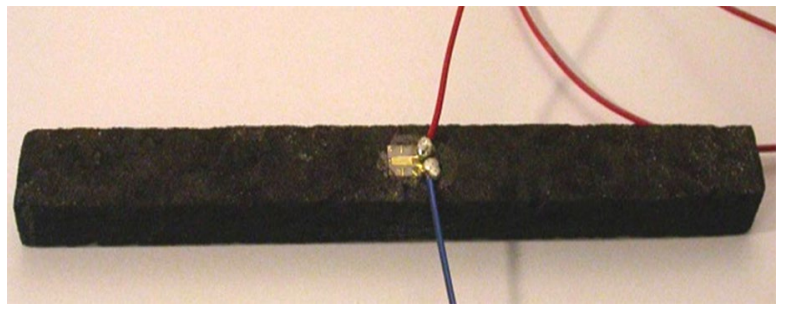


Table 1 Facility parameters for

\begin{tabular}{ll}
\hline Gas Mass flow rate $(\mathrm{g} / \mathrm{s})$ & 101 \\
\hline Reservoir pressure $(\mathrm{hPa})$ & 3750 \\
Reservoir temperature $(\mathrm{K})$ & 6462 \\
Specific enthalpy $(\mathrm{MJ} / \mathrm{kg})$ & 15.9 \\
Nozzle throat diameter $(\mathrm{mm})$ & 29 \\
Nozzle exit diameter $(\mathrm{mm})$ & 50 \\
\hline
\end{tabular}

PWT testing of other carbon-phenolic ablators like ZURAM [30, 45], ASTERM [46], and PICA [47].

All facility and test conditions were listed in Tables 1,2. The bottom of the sample was glued to a steal flange with a proper binder (Ceramabond 685-N, a low thermal conductivity $\mathrm{ZrO}_{2}$ containing adhesive material), so that the samples can be arranged in the holder as shown in Fig. 3. The samples were measured and weighted before and after the test for evaluating the surface recession and the weight change due to the high enthalpy plasma exposure. The temperature at the exposed surface and at the back surface of the samples were constantly recorded during the test. For the back temperature a k-thermocouple was positioned at the bottom of the sample, fixed to it thanks to the binder which connect the sample with the holder. Thus the distance between the point for the measurement of the surface temperature and the point for the measurement of the bottom temperature is $4 \mathrm{~cm}$ at the beginning of the test (then the recession has to be considered).

The surface temperature was recorded by two different pyrometers aligned to the center of the samples: a spectral pyrometer KTR 1485-Z by Dr. Maurer, for which the emissivity was set at 0.85 , and a two-color pyrometer QKTR 1485 by Dr. Maurer. Both pyrometers can operate in a temperature range of $900-3000{ }^{\circ} \mathrm{C}$ and have a sensitivity wavelength of $1 \mu \mathrm{m}$.

The heat flux was evaluated with a gauge based on the calorimeter technique: a cylindrical probe is exposed to the gas flow and its surface is cooled down with water at a known flow rate. The steady-state, cold-wall heat flux is determined thanks to an energy balance of the measured flow rate and inlet and outlet water temperature [44]. The tests were performed at two different levels of heat fluxes: 6 and $13 \mathrm{MW} / \mathrm{m}^{2}$.

\subsection{Finite Element Analysis for Ablation and Pyrolysis Phenomena}

The proposed FE model aims at providing an instrument able to predict the ablative material behavior validated by the rebuilding of the Plasma Wind Tunnel test. Finite element analysis is able to predict the performance of a structure for known boundary conditions and external loads. The peculiarity of a charring ablative material is the concurrence of mechanical and thermal solicitations with a surface recession, a density variation and the

Table 2 Test parameters for the tests

\begin{tabular}{lll}
\hline & Test condition 1 & Test condition 2 \\
\hline Distance from nozzle exit $(\mathrm{mm})$ & 160 & 75 \\
Pitot pressure $(\mathrm{hPa})$ & 210 & 840 \\
Cold wall heat flux rate $\left(\mathrm{MW} / \mathrm{m}^{2}\right)$ & 6.1 & 12.8 \\
\hline
\end{tabular}


Fig. 3 Ablative samples positioned in the holder for the PWT test

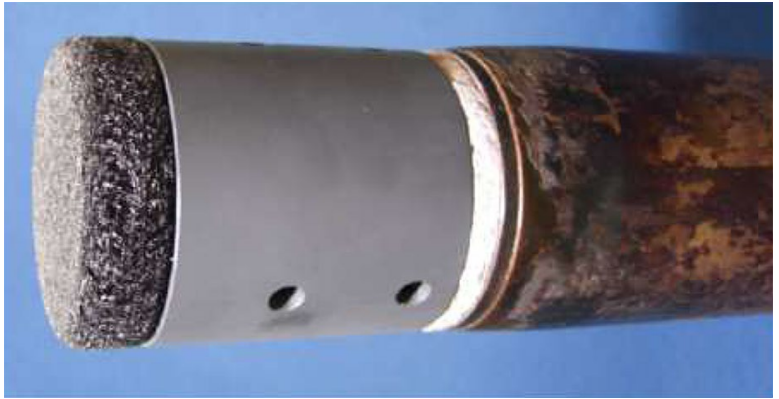

pyrolysis reaction which generates gasses flowing throughout the material [48-50]. The thermo-physical and chemical characteristics of three different areas (a virgin material, a charred material and a zone in which the pyrolysis is still active and the material is partially in a charred state) are mandatory input for a FE model which has to deal with ablation and pyrolysis phenomena. Furthermore the boundary conditions about temperature, pressure and heat flux have to be taken into account $[14,37,51]$. In this work the FE simulation was carried out with a commercial FEM software for structural and thermal problems, SAMCEF v.16.9, released by SAMTECH, a Belgium company controlled by SIEMENS. SAMCEF is able to deal with linear and non-linear statics and dynamics problems and consists of several modules connected to a pre- and a post-processor. Amaryllis is the module of SAMCEF conceived for dealing with ablation and pyrolysis phenomena for a solid material. It can elaborate thermo-physical responses for 1D, 2D and for axial-symmetric geometries. Several boundary conditions can be imposed: convective, radiative or directly applied heat fluxes. The module is able to simulate mechanical, chemical and phase-change ablation, applying an appropriate re-mesh strategy to the initial mesh. For this study the re-mesh strategy provides for a shrinkage of the mesh elements according to the calculated recession. Once all necessary inputs are provided and the mesh and re-mesh strategy are set up, the post-processor can elaborate several outputs: the temperature field, the density variation as function of time and spatial coordinates, the gas flow as function of time, the surface recession. For a thermal problem with ablation and pyrolysis phenomena, Amaryllis solves a three equations system (heat balance, the conservation of the mass and the kinetic of pyrolysis equation) written as function of three dependent variables: temperature $T$, pressure $p$, density $\rho[52,53]$. The conservation of the mass is influenced by pyrolysis reaction which causes a variation of the material density and the formation of pyrolysis gasses while gas mass variation is considered negligible compared to the solid mass variation. The pyrolysis gas is assumed to behave as a perfect gas [37], thus the motion of a fluid throughout a permeable solid was modeled by the Darcy equation. The heat balance equation is written by considering the conductivity heat exchange according to Fourier equation. The thermal conductivity depends on virgin and char thermal conductivity ant it is also a function of the extent of conversion. At last, the pyrolysis reaction has to be taken into account. The velocity of the chemical reaction can be written according to Arrhenius formulation. The reagent concentration can be written considering the solid density $\rho$ for a generic time $t$, the virgin material density $\rho_{v}$ and the char material density $\rho_{c}$. Furthermore the $n$-th kinetic model is the more common for a phenolic resin [15] and it is employed also in the software algorithm. The three conservation Eqs. $(2,3,4)$ have to be solved by Amaryllis for obtaining the trend of temperature, pressure and density inside the considered sample. 


$$
\begin{gathered}
\text { Heat balance } H_{p} A \rho_{v}{ }^{1-n}\left(\rho-\rho_{c}\right)^{n} e^{-\frac{E_{a}}{R T}}+\rho c \dot{T}=\nabla(\lambda \nabla T)+K_{p} \nabla h^{g} \nabla p \\
\text { Conservation of mass }-A \rho_{v}{ }^{1-n}\left(\rho-\rho_{c}\right)^{n} e^{-\frac{E_{a}}{R T}}=\nabla\left(K_{p} \nabla p\right) \\
\text { Pyrolysis kinetics } \frac{\dot{\rho}}{\rho_{v}}=-A\left(\frac{\rho-\rho_{c}}{\rho_{v}}\right)^{n} e^{-\frac{E_{a}}{R T}}
\end{gathered}
$$

All the required input parameters for the finite element modeling are presented in Table 3.

All these parameters required for the FE simulation need to be experimentally calculated: a part of the required parameters were evaluated in this work or in previous experimentations, and the missing parameters were selected from the TACOT database. TACOT is a theoretical model of a carbon phenolic ablator elaborated during a collaboration between NASA and ESA: it was developed by simulating a carbon felt impregnated with phenolic resin with a density of $0.27 \mathrm{~g} / \mathrm{cm}^{3}$ [37].

The virgin and charred material densities were evaluated by measuring the volume and the weight of specimens of virgin and charred material for each kind of ablator (RF and MF). The charred density was obtained by charring small cubes of ablative material in inert atmosphere (nitrogen) at $900{ }^{\circ} \mathrm{C}$ for $1 \mathrm{~h}$. The chemical kinetic parameters are considered equal for both ablators: this approximation is acceptable because pyrolysis involves only the phenolic resin. The procedure for their calculation and their values were reported in a previous work [15]. The thermal conductivity of the virgin and charred materials were evaluated as explained previously, and the possible variation in the radial and axial thermal conductivity are not taken into account. This approximation is plausible for MF, because of the random orientation of carbon fibers, but it can be a significant hypothesis for RF materials. According to the datasheet of the RFA Sigratherm carbon felt, the difference in thermal conductivity is limited (max. $+20 \%$ in radial direction) and the contribution of

\begin{tabular}{|c|c|c|}
\hline Chemical kinetic parameters & $\begin{array}{l}\text { Activation energy } \\
\text { Frequency factor } \\
\text { Order of reaction } \\
(i=1,2,3)\end{array}$ & $\begin{array}{l}E_{a i} \\
A_{i} \\
n_{i}\end{array}$ \\
\hline Physical properties of virgin and char material & $\begin{array}{l}\text { Virgin density } \\
\text { Char density } \\
\text { Char permeability } \\
\text { Virgin porosity }\end{array}$ & $\begin{array}{l}\rho_{\mathrm{v}} \\
\rho_{\mathrm{c}} \\
\nu^{\mathrm{c}} \\
\Omega^{\mathrm{v}}\end{array}$ \\
\hline $\begin{array}{l}\text { Thermal properties of virgin and char material as func- } \\
\text { tion of temperature }\end{array}$ & $\begin{array}{l}\text { Virgin enthalpy } \\
\text { Char enthalpy } \\
\text { Virgin thermal conductivity } \\
\text { Char thermal conductivity }\end{array}$ & $\begin{array}{l}h^{\mathrm{v}}(T) \\
h^{\mathrm{c}}(T) \\
\lambda^{\mathrm{v}}(\mathrm{T}) \\
\lambda^{\mathrm{c}}(\mathrm{T})\end{array}$ \\
\hline $\begin{array}{l}\text { Thermal properties of pyrolysis gas as function of tem- } \\
\text { perature and pressure }\end{array}$ & Pyrolysis gas enthalpy & $\mathrm{h}^{\mathrm{g}}(\mathrm{p}, \mathrm{T})$ \\
\hline Physical properties of pyrolysis gas & $\begin{array}{l}\text { Molecular mass } \\
\text { Dynamic viscosity }\end{array}$ & $\begin{array}{l}\mathrm{M}^{\mathrm{g}} \\
\mu^{\mathrm{g}}\end{array}$ \\
\hline
\end{tabular}
the phenolic resin in terms of thermal conductivity is the same in all directions because of

Table 3 Input parameters for material and gas required by SAMCEF Amaryllis 
Table 4 Initial conditions imposed in the finite element model

\begin{tabular}{lll}
\hline & $\dot{q}=6.1 \frac{M W}{m^{2}}$ & $\dot{q}=12.8 \frac{M W}{m^{2}}$ \\
\hline $\mathrm{T}_{\text {in }}$ & $300 \mathrm{~K}$ & $300 \mathrm{~K}$ \\
$\mathrm{p}_{\text {in }}$ & $0.21 \mathrm{bar}$ & $0.84 \mathrm{bar}$ \\
$\rho_{\text {in }}$ & $0.3 \mathrm{~g} / \mathrm{cm}^{3}$ & $0.3 \mathrm{~g} / \mathrm{cm}^{3}$ \\
\hline
\end{tabular}

the homogeneous resin distribution. All the other missing parameters were selected from TACOT database [37]. Initial and boundary conditions are mandatory for solving the differential equations system of the Finite Element model ((2)(3)(4)). The initial temperature was set equal to the one measured in the test chamber at the beginning of the test, the initial density is the one of the virgin material and the initial chamber pressures were selected according to the collected PWT data, as a function of the heat flux conditions. The pressures were measured during the test with a Pitot probe. All initial conditions are shown in Table 4. The axisymmetric geometry of the sample for PWT test has three different boundary zones (Fig. 4): the zone 1 represents the symmetric axis and for this reason the software imposes automatically an adiabatic condition; the zone 2 represent the areas in which the sample is connected with the holder and a thermal insulating material is used to guarantee the holder protection. For this reason an approximated adiabatic condition was considered plausible also for the zone 2. Moreover the zone 3, drawn in red in Fig. 4, represents the areas in which the specimen is hit by the heating flux and the convective and radiation exchanges take place. The thermal and mechanical boundary conditions have to be imposed in this area: the pressure is known and equal to the pressure measured by the

Fig. 4 Schematic representation of the different boundary zones for the ablative samples

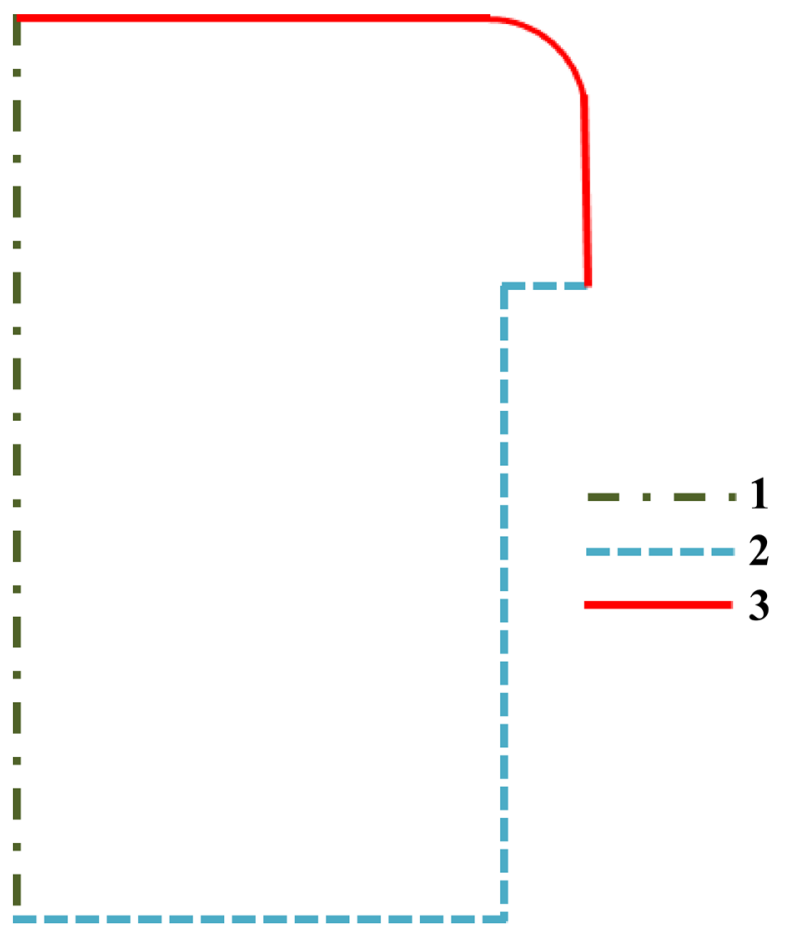


Pitot probe during the test thus it is imposed as a Dirichelet boundary condition. The thermal boundary conditions were imposed by applying the heating flux expressed in enthalpic form: for this reason the convective coefficient in enthalpic form $C_{h}$ can be defined by knowing the wall enthalpy $H_{w}$, the cold wall heat flux $\dot{q}$ and the recovery enthalpy $H_{r}$. The relation among these values is shown hereafter

$$
C_{h}=\frac{\dot{q}}{H_{r}-H_{w}}
$$

In this case some approximations were assumed: i) the recovery enthalpy was considered equal to the total enthalpy (this means that Prandtl number is not unity and the phenomena of the viscous heating are neglected [38]) and ii) the cold wall enthalpy was approximated with the enthalpy of the gases at room temperature, supposing a thermal equilibrium between pyrolysis gases and the solid material $[2,54,55] . C_{h}$ was set constant for the upper (stagnation) surface, and reduced for the lateral exposed surface according to the data provided by TACOT database [37]. The definition of the heat transfer coefficient does not take into account the effect of the gas blowing due to the pyrolysis phenomena $[53,56]$. For this reason a blowing correction factor $\check{\lambda}$ was applied in Amaryllis and it was set equal to 0.5 in accordance with the laminar flow condition used for TACOT simulation by T. Van Eekelen et al. in [37]. The reference temperature for the radiative exchange is the initial temperature in the chamber $\left(T_{r e f}=300 \mathrm{~K}\right)$ and the adopted function and values for the emissivity refer to TACOT database. [37] The recession rate is another important condition to be imposed. The recession can take place only in zone 1 and it is governed by a function called "Non dimensional ablation speed" $B_{C}$, according to the approach proposed for the first time in 1968 by Kendall et al. [57].

The $B_{C}$ is a set of surface recession data provided in form of matrices and generally generated by thermochemical equilibrium programs assuming a chemical equilibrium between the reacting surface and the atmospheric gas [58]. $B_{C}^{\prime}$ depends on i) the pyrolysis gases and environment composition, ii) the allowable condensed and gaseous species and iii) the possible reactions occurring among them [59]. In this work $B_{C}$ refers to TACOT database [37] and it is a function of pressure, temperature and of the matrix $B_{g}^{\prime}$ which is related to the quantity and nature of the pyrolysis gases [60].

The simulation was carried out for samples tested at $6 \mathrm{MW} / \mathrm{m}^{2}$. The main differences between the two samples are the thermal conductivity, because of the different structure of the carbon felts, and the mechanical properties which influences the recession rate of the material. For this reason the thermal conductivity was evaluated with a laser flash method, while the mechanical properties were evaluated with a four points bending test, even if the mechanical properties are not required for this finite element model.

\section{Results and Discussion}

\subsection{Microstructure of the Ablative Materials}

All manufactured samples show a density of about $0.30( \pm 0.01) \mathrm{g} / \mathrm{cm}^{3}$. The microstructure of the ablative materials was observed with a scanning electron microscope (Tescan Mira 3 ) in order to evaluate the goodness of the infiltration process. The observation of the cross section of the whole samples enlightens the good distribution of the resin which is present in the inner part of the samples as in the outer areas. The micrographs in Fig. 5 compare 

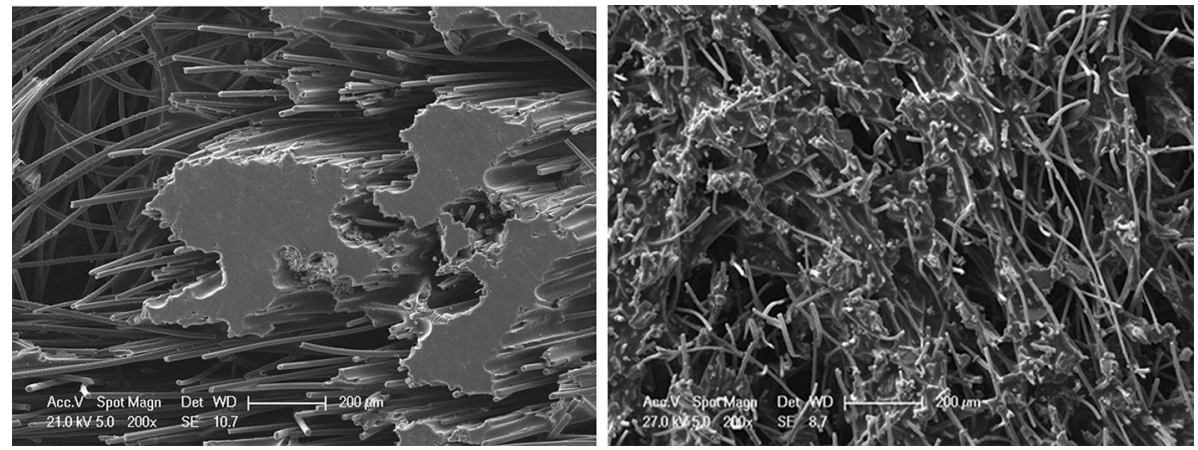

Fig. 5 Microstructure of ablative materials with RFA Sigratherm (on the left) and MFA Sigratherm (on the right)

the microstructure of the inner part of samples with RFA and MFA Sigratherm carbon felts: the different structure and orientation of the carbon fibers influence the distribution of the resin inside the samples: in MF samples the resin has a more homogeneous distribution, while in RF samples the resin distributes in agglomerates of some mm while other areas remain partially empty of resin. The distribution obtained with MFA carbon felt is obviously preferred because it is supposed to guarantee more homogeneous properties of the material.

\subsection{Thermal Conductivity and Mechanical Properties}

Results about the thermal conductivity of the MF and RF ablators are reassumed in Fig. 6 and refer to the through-the-thickness direction of the original board. Carbon-phenolic ablators decompose during the high temperature heating with an inevitable change in density: this phenomenon was evaluated and considered for the calculation of the thermal conductivity data starting from thermal diffusivity values. The temperature range for the pyrolysis reaction is $300{ }^{\circ} \mathrm{C}<\mathrm{T}<900{ }^{\circ} \mathrm{C}$ [15], thus for the first two evaluated points $\left(20^{\circ} \mathrm{C}\right.$ and

Fig. 6 Thermal conductivity for ablative samples manufactured with RFA and MFA Sigratherm carbon felt

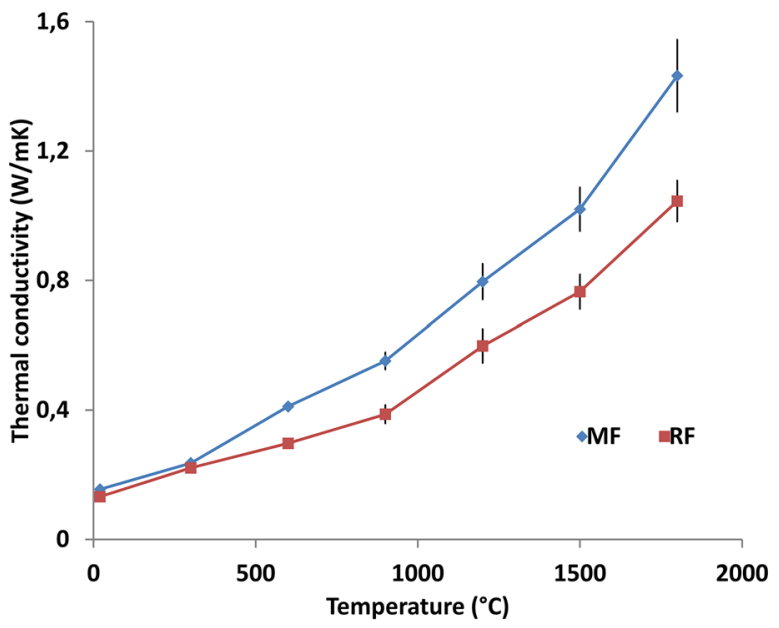


$300{ }^{\circ} \mathrm{C}$ ) the density was the same of the virgin material, while for $\mathrm{T}>900{ }^{\circ} \mathrm{C}$ the density of the charred material was considered. When the laser flash analysis is performed at $600{ }^{\circ} \mathrm{C}$ the material is partially pyrolyzed, thus the density can be approximated considering the extent of the pyrolysis reaction evaluated by thermogravimetric analysis performed in inert (Ar) atmosphere with a heating rate of $20^{\circ} \mathrm{C} / \mathrm{min}$.

The MF ablator shows higher thermal conductivity and this is probably due to the different distribution of the carbon fibers. The distribution of the resin inside the carbon felt can influence the thermal conductivity too: in particular a lower thermal conductivity is expected when the resin has a more homogeneous distribution but in this case the better distribution of the resin inside the MF does not compensate for the effect of the fibers orientation. The difference in thermal conductivity is negligible for temperature lower than $300{ }^{\circ} \mathrm{C}$, but for higher temperature this difference becomes more significant.

The mechanical properties at room temperature of the MF and RF ablators were assessed by 4-point bending tests: all the samples exhibited linear elastic behavior and a brittle failure mode. The values of Young's modulus and flexural strength are reassumed in Fig. 7. Ablators with RFA carbon felts show higher mechanical properties in terms of both stiffness and strength: while the Young's modulus of the two materials is quite similar considering the standard deviation, the maximum strength of the RF ablators is more than twice the MF ablators' one. The orientation of the fibers and their stratification in the RFA carbon felt are considered to be the main reasons for the higher mechanical properties of RF ablators.

\subsection{Plasma Wind Tunnel Test Results}

The plasma wind tunnel test results are reassumed in Table 5, while Fig. 8 shows the samples before and after the test: both MF and RF samples show a uniform recession when tested at $6 \mathrm{MW} / \mathrm{m}^{2}$, while an heat flux of $13 \mathrm{MW} / \mathrm{m}^{2}$ causes irregular and intense surface recession. Thus when the tests were performed at the highest heat flux the excessive wearing out of the material compromised the goodness of the measurements and for RF sample it was necessary to interrupt the test ahead of time in order to preserve the instrumentation (and for this reason the testing time was $9.6 \mathrm{~s}$ for RF and $12.8 \mathrm{~s}$ for MF). When the same kind of sample is tested at $6 \mathrm{MW} / \mathrm{m}^{2}$ the increment in testing time from $24 \mathrm{~s}$ to 30 leads to

Fig. 7 Mechanical tests results for RF and MF ablative materials

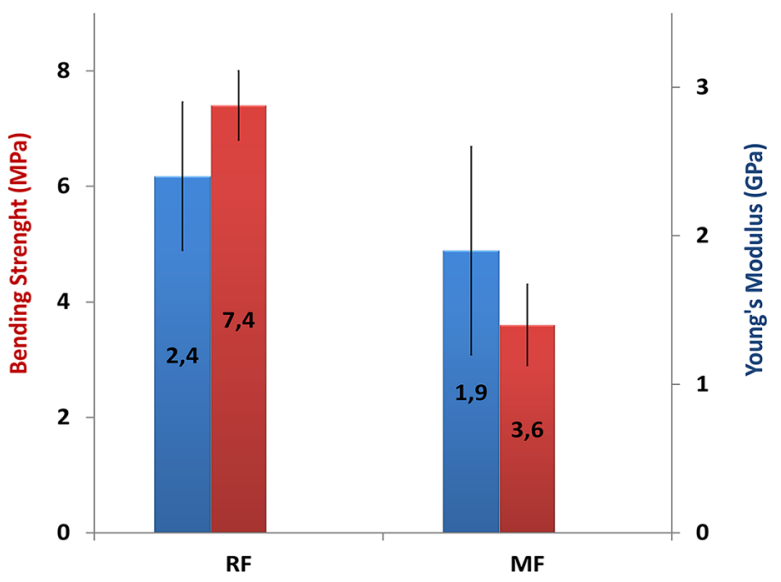


Table 5 Results of the PWT test supplied by DLR (*test interrupted ahead of time)

\begin{tabular}{lcclll}
\hline Sample & Test duration (s) & $\begin{array}{l}\text { Mass loss } \\
(\mathrm{g})\end{array}$ & $\begin{array}{l}\text { Surface recession } \\
(\mathrm{mm})\end{array}$ & $\begin{array}{l}\text { Mass loss rate } \\
\left(\mathrm{g} /\left(\mathrm{m}^{2} \mathrm{~s}\right)\right.\end{array}$ & $\begin{array}{l}\text { Reces- } \\
\text { sion rate } \\
(\mathrm{mm} / \mathrm{s})\end{array}$ \\
\hline RF1 & 24.0 & 4.92 & 5.0 & 104.4 & 0.208 \\
RF2 & 29.8 & 5.61 & 5.6 & 95.8 & 0.188 \\
RF3 & $9.6^{*}$ & 13.17 & -- & -- & -- \\
MF1 & 24.4 & 4.94 & 5.1 & 103.1 & 0.202 \\
MF2 & 30.2 & 5.82 & 5.7 & 98.1 & 0.189 \\
MF3 & 12.8 & 21.31 & -- & - & -- \\
\hline
\end{tabular}

a slight increment in the mass loss and surface recession; the mass loss rate and the recession rate are different for the two exposure times: this means that the variation is not linear, but it is more intense at the beginning of the test. RF and MF samples tested at $6 \mathrm{MW} / \mathrm{m}^{2}$ show similar behavior in terms of mass loss and recession rate. The same parameters cannot be calculated for the samples tested at $13 \mathrm{MW} / \mathrm{m}^{2}$ because of the intense and irregular recession. Temperature at the surface and at the bottom of the samples were recorded during the tests by a pyrometer and a k-thermocouple respectively and the data are reassumed in the graphs in Fig. 9 (data about MF3 and RF3 are not available). The surface temperature reaches the higher value for RF samples at the beginning of the test $\left(2793{ }^{\circ} \mathrm{C}\right.$ for RF1 and $2690{ }^{\circ} \mathrm{C}$ for RF2) and, then, it decreases slightly during the heating reaching a value of about $2620-2610{ }^{\circ} \mathrm{C}$. For MF samples the surface temperature is always quite constant during the test and the maximum value is $2580{ }^{\circ} \mathrm{C}$ for MF1 and $2606{ }^{\circ} \mathrm{C}$ for MF2. After the heat flux exposure, the pyrometer and the thermocouple continued to record the temperature until $100 \mathrm{~s}$. The cooling of the surface is very fast thanks to the radiating exchange, and it can be recorded until $900{ }^{\circ} \mathrm{C}$ which is the lower limit of the pyrometer measurement range. The MF samples reach faster the minimum temperature of $900{ }^{\circ} \mathrm{C}$ probably because of their higher thermal conductivity (Fig. 6). The temperature at the bottom of the samples

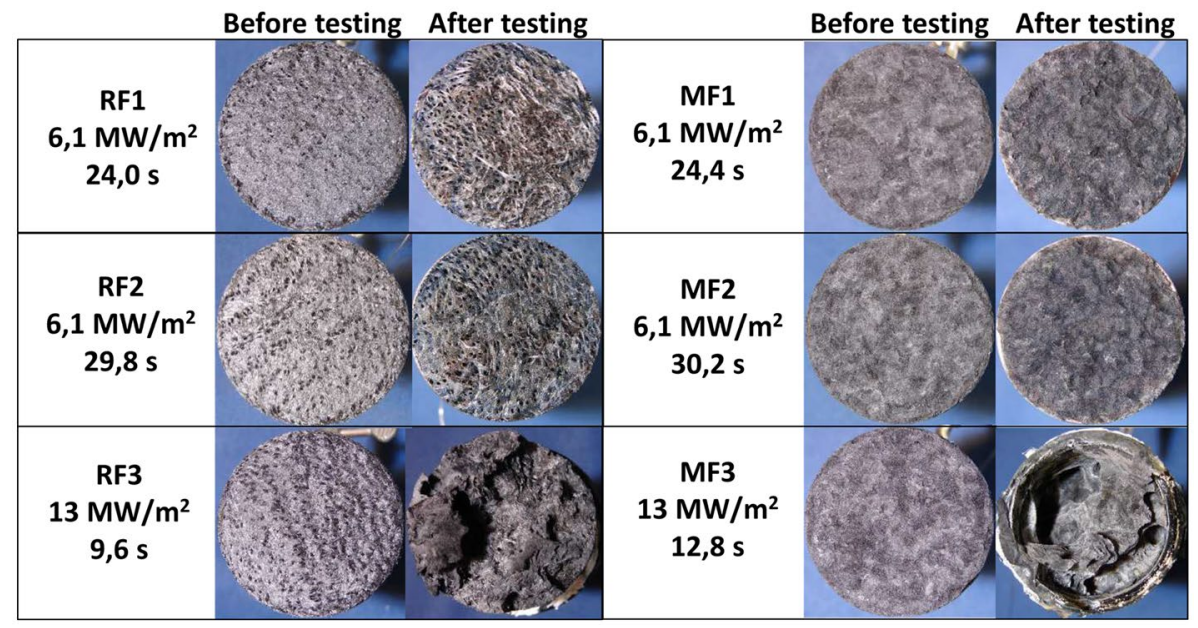

Fig. 8 Samples tested in the PWT facility, before and after testing (courtesy of Thales Alenia Space Italia) 

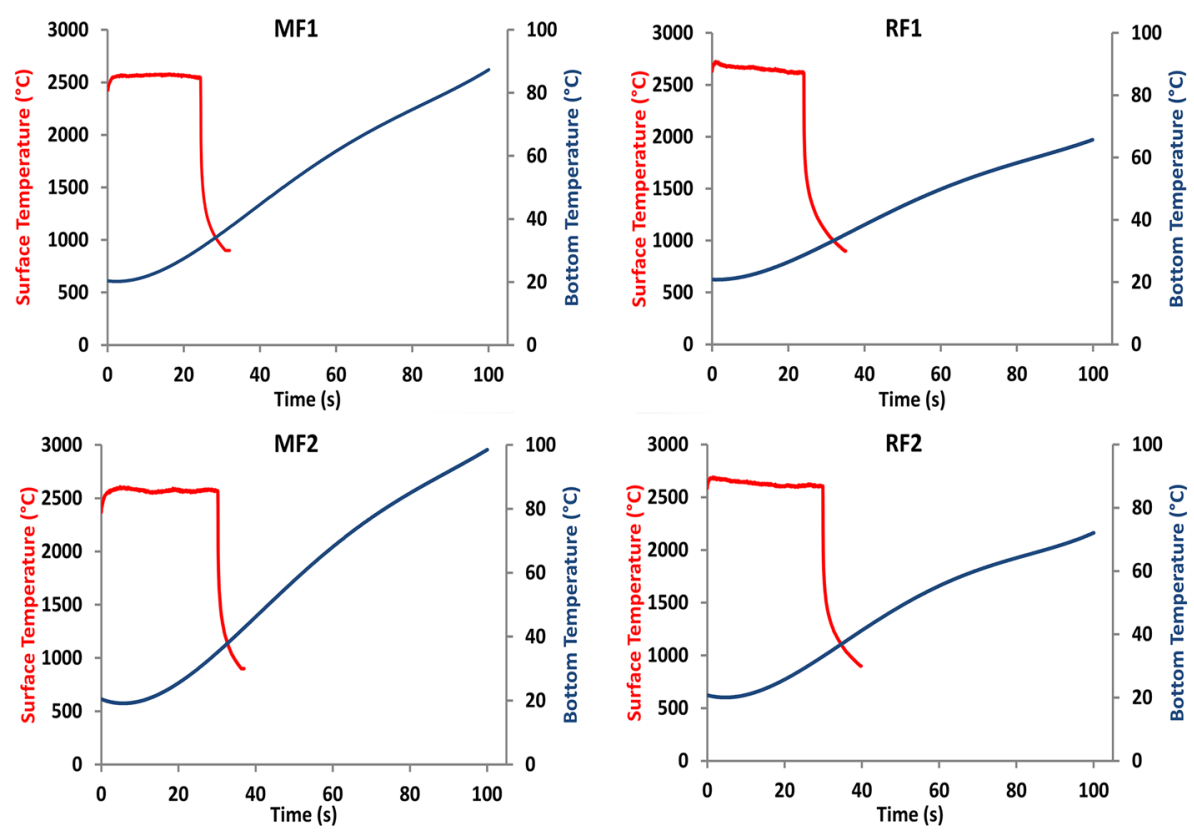

Fig. 9 Surface and bottom temperature recorded during the PWT tests

continues to increase also during the cooling but it never becomes higher than $100{ }^{\circ} \mathrm{C}$. Considering the back temperature, the RF ablative material show the best results with a maximum temperature of $72{ }^{\circ} \mathrm{C}$ for the sample with the longer exposure, while the MF samples show a back temperature always higher and, for the longer exposure, it reaches $98^{\circ} \mathrm{C}$ at the end of the cooling time. In future experimental tests the back temperature data will be recorded until the complete cooling-down of the sample in order to obtain further information on the thermal behavior of the tested materials.

\subsection{Finite Element Analysis}

In Fig. 10 the results about surface recession, the temperature field and the distribution of the density inside the material in each point of the geometry for the investigated material MF2 are shown at the end of the exposure time. The image on the left shows in colors the shrunk mesh of the recessed material and in green the mesh of the original geometry. The other two images (at the center and on the right) show the temperature and density distribution at the end of the exposure time, but without considering the shrinkage of the mesh caused by the ablation. In this way the images provide a more appreciable observation of the results. The maximum surface recession can be compared with the real one evaluated after the PWT test: in this case the FE model predicts an underestimated recession of $4.34 \mathrm{~mm}$ while the real one is of $5.7 \mathrm{~mm}$ (a percentage error of 24\%). The underestimation could be attributed to the implementation of the TACOT $B_{C}^{\prime}$ data [37], providing a rough approximation of the nondimensional ablation speed of Sapienza material. On the contrary, the maximum temperature was slightly overestimated because for the FE model the ablator reaches a maximum temperature of $2632{ }^{\circ} \mathrm{C}$ versus the $2606{ }^{\circ} \mathrm{C}$ recorded during the test 

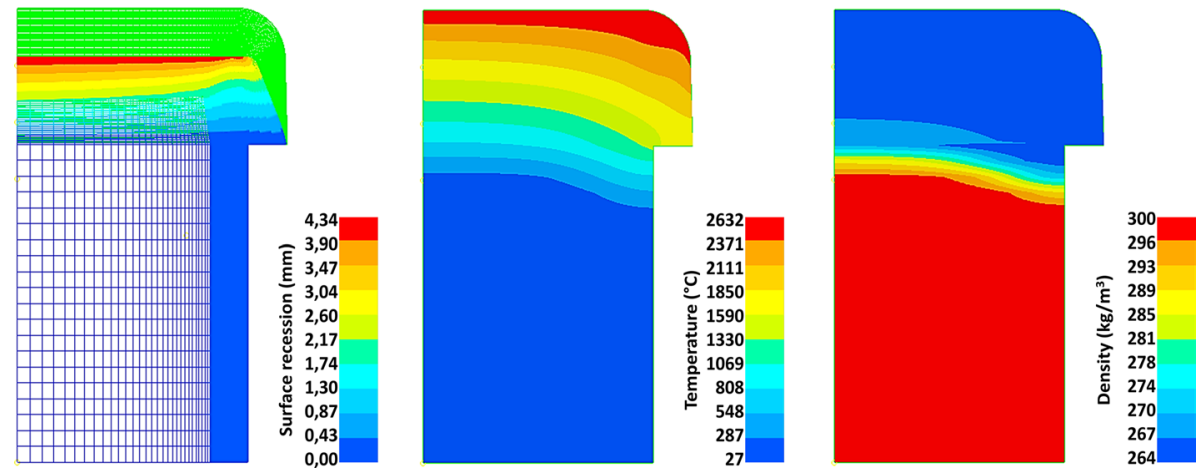

Fig. 10 FE analysis results for MF2: surface recession (with shrunk mesh in colors and original mesh in green), temperature and density (no shrunk mesh)

in the DLR facility. Thus, considering a percentage error of $1 \%$, there is a good agreement between the results at the PWT and the results rebuilt with the FE model. These results are obtained considering the same values for the in plane and through-the-thickness thermal conductivity, thus slightly underestimating the radial thermal conductivity. The results of the finite element analysis show the presence of a limited thermal gradient in the radial direction, thus confirming that the approximation for the in-plane conductivity does not affect significantly the result of this specific simulation. This approach was also proposed by other works [2] confirming that the axial conductivity is considered strictly dominant for an ablator exposed to a heating flux in a PWT facility. The software is able to evaluate the trend of the density within the sample (Fig. 10 on the right) and this information can be very useful to understand the thickness of the pyrolyzing area. This results of the numerical model are not directly comparable with post-experimental data: after the removal of the heat flux, the pyrolyzed layer can be modified by the propagation and evolution of the thermal field causing a further increase in the char thickness. In Table 6 the experimental values of surface recession and temperature at the end of test are compared with the results of the FEM analysis: in each case the FE model underestimates the surface recession and overestimates the final temperature. The choice to consider final temperature and not the maximum temperature is due to the initial sudden increase of temperature during the experimental test, in particular for RF samples. This phenomenon can be due to the procedure for the exposure of the sample in the plasma: the sample is positioned inside the flux when it is already active, thus there is an undesired heating phase during the positioning process which cannot be simulated by the FEM software. For this reason it is more

Table 6 Surface recession, final temperature for DLR test and FEM analysis

\begin{tabular}{llllll}
\hline & \multicolumn{2}{l}{ Surface recession $(\mathrm{mm})$} & & \multicolumn{2}{l}{ Final temperature } \\
& & & & & \multicolumn{2}{c}{$\left({ }^{\circ} \mathrm{C}\right)$} \\
\cline { 5 - 6 } & DLR & FEM & & DLR & FEM \\
\hline$R F 1$ & 5.0 & 3.79 & & 2613 & 2597 \\
$R F 2$ & 5.6 & 4.21 & & 2610 & 2603 \\
$M F 1$ & 5.1 & 3.91 & & 2545 & 2570 \\
$M F 2$ & 5.7 & 4.34 & & 2564 & 2578 \\
\hline
\end{tabular}



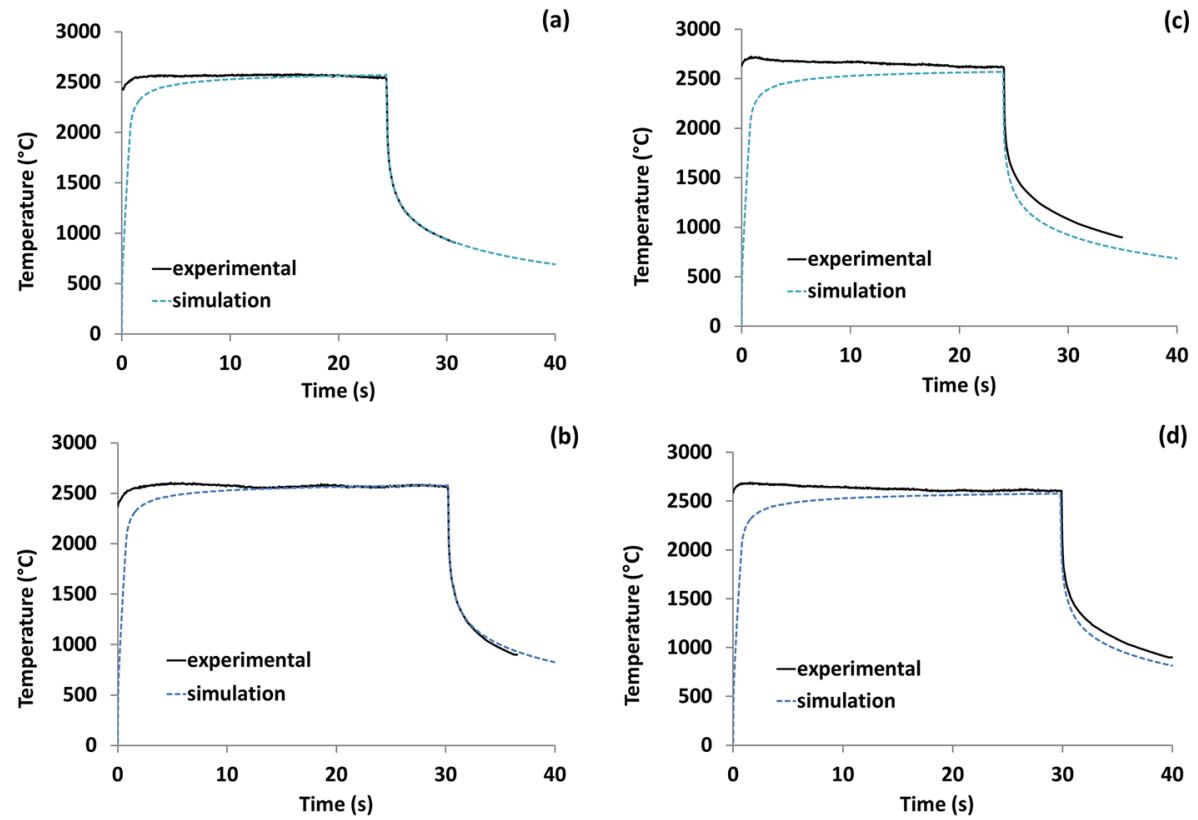

Fig. 11 Surface temperature recorded during PWT test and simulated with SAMCEF Amaryllis FEM ((a) RF1, (b) RF2, (c) MF1, (d) MF2)
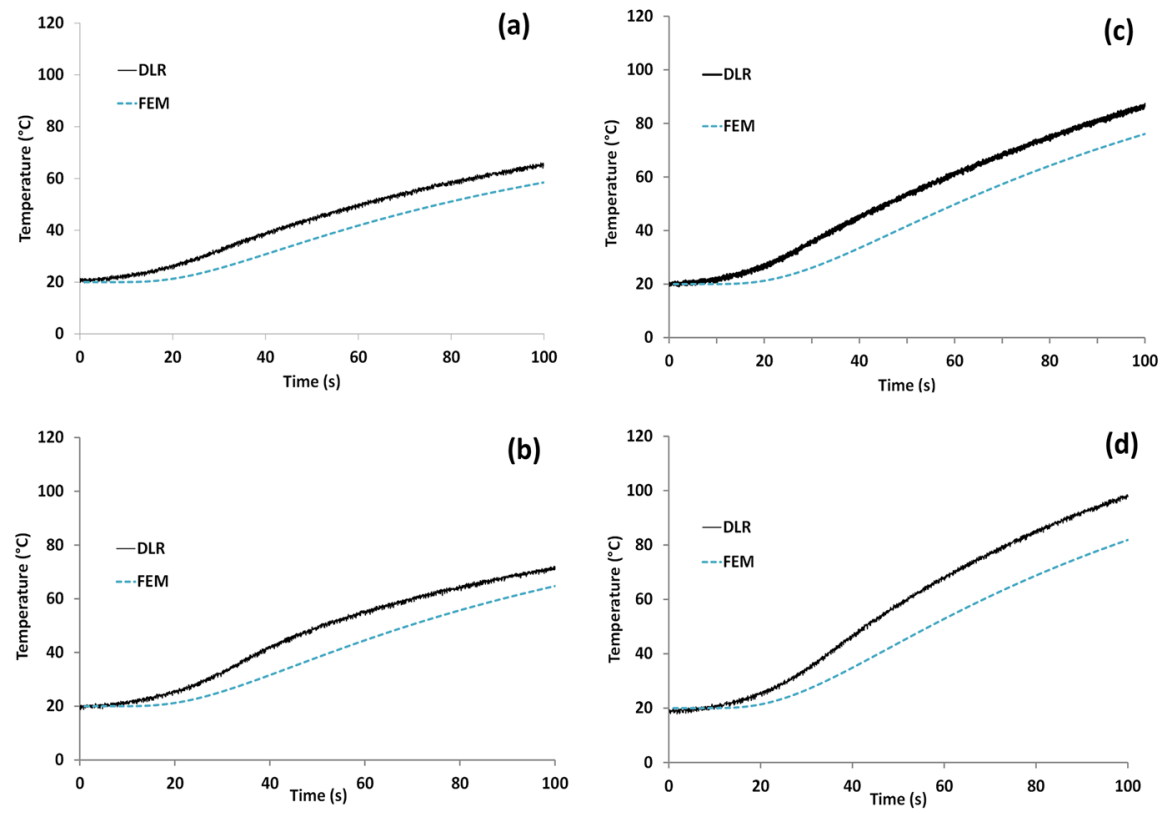

Fig. 12 Back temperature recorded during PWT test and simulated with SAMCEF Amaryllis FEM ( (a) RF1, (b) RF2, (c) MF1, (d) MF2) 
Table 7 Comparison of the performance of some carbon-phenolic ablators with Sapienza Ablative Material $\left(\mathrm{SAM}^{*}\right)$ considering the MF sample

\begin{tabular}{|c|c|c|c|c|c|c|}
\hline Ablator & Density $\left(\mathrm{g} / \mathrm{cm}^{3}\right)$ & $\begin{array}{l}\text { Heat flux } \\
\left(\mathrm{MW} / \mathrm{m}^{2}\right)\end{array}$ & Testing time (s) & $\begin{array}{l}\text { Recession } \\
\text { rate }(\mathrm{mm} / \mathrm{s})\end{array}$ & PWT facility & REF \\
\hline \multirow[t]{2}{*}{ PICA } & 0.270 & 5.5 & 30 & 0.173 & IHF & [47] \\
\hline & 0.265 & 13.65 & 17 & 0.312 & IHF & [25] \\
\hline ASTERM & 0.350 & 4.1 & 25 & 0.032 & IRS & [46] \\
\hline \multirow[t]{2}{*}{ ZURAM } & 0.380 & 4.1 & 25 & 0.043 & IRS & [46] \\
\hline & 0.370 & 12 & 29 & 0.265 & IRS & [30] \\
\hline \multirow[t]{2}{*}{$S A M^{*}$} & 0.300 & 6 & 24 & 0.202 & DLR & \\
\hline & 0.300 & 13 & 12 & -- & DLR & \\
\hline
\end{tabular}

appropriate to compare the temperatures recorded just before the end of the test, when there are no more unsteadiness in the recorded experimental temperature. The final temperatures are very similar for the experimental test and the simulation with a maximum gap of $25^{\circ} \mathrm{C}$, as shown in Table 6 and in Fig. 11. Furthermore the cooling phase of the exposed surface was recorded at DLR facility and simulated with the FEM software: the trends of the simulated and experimentally recorded temperatures on the surface of the materials are very similar, in particular for MF samples. The back temperatures recorded during the PWT test were compared with the temperatures at the bottom of the samples simulated by the FE model (Fig. 12): the trend of the simulated temperatures is quite similar to the experimental results, but each back temperature is always underestimated.

\section{Conclusions}

Two different kinds of carbon-phenolic ablators with a density of $0.3 \mathrm{~g} / \mathrm{cm}^{3}$ were manufactured, characterized and tested in a PWT facility (DLR Germany). These materials distinguish by the kind of carbon felt used as reinforcing phase: RFA Sigratherm for RF samples and MFA Sigratherm for MF samples. The process for the manufacturing of these materials allowed for obtaining ablators with a good distribution of the phenolic resin inside the carbon felts, in particular for the MF samples, while more agglomerates were found for the RF samples. In both cases, the phenolic resin is homogeneously present in the outer and in the inner part of the samples. The thermal conductivity was evaluated by the laser flash method, resulting in a higher thermal conductivity of the MF samples, in particular at higher temperatures. Four points bending tests provided information about the mechanical properties and enlighten an higher stiffness and strength for the RF samples.

The PWT tests, conducted in the DLR facility at different heat fluxes, show that these ablators are adequate for the exposure at an heating flux of $6 \mathrm{MW} / \mathrm{m}^{2}$ guarantying an important fall of temperature of more than $2400{ }^{\circ} \mathrm{C}$ from the exposed surface to the back of the samples, considering a total thickness of $4 \mathrm{~cm}$ and an exposure time of about $30 \mathrm{~s}$, which is a performance comparable to the more common carbon-phenolic ablators like PICA, ASTERM or ZURAM [9, 46, 61-63]. A comparison of the Sapienza Ablative Material with these well-known ablators is proposed in Table 7 showing comparable performance when tested at $6 \mathrm{MW} / \mathrm{m}^{2}$, according to literature data. Even if the heat flues were different, for the lower heat flux the Sapienza Ablative Material shows promising performances considering the comparable recession rate with the PICA's one even if the heat 
flux for PICA is slightly lower. ASTERM and ZURAM show best performance, but their density is higher and the heat flux is lower. The performances of ZURAM and PICA were reported also for an heat flux of $12-13 \mathrm{MW} / \mathrm{m}^{2}$. The results presented in Table 7 show that they are able to withstand high heat fluxes without uncontrolled erosion; nevertheless the test conditions are not perfectly comparable, especially in terms of stagnation pressure (e.g. for SAM twice than PICA) and gas flow rate which can influence strongly the recession rate $[25,30,45]$.

Both surface recession and mass loss are comparable for RF and MF samples, while RF sample seems to guarantee an higher thermal shielding effect thanks to its lower thermal conductivity. Furthermore, these materials cannot bear an heating flux as high as $13 \mathrm{MW} /$ $\mathrm{m}^{2}$, which causes a sudden and catastrophic recession. With a commercial finite element analysis software, SAMCEF Amaryllis, the Plasma Wind Tunnel tests were rebuilt: the trend of temperatures on the back and on the surface were well reproduced and an acceptable agreement with the experimental surface recession was also obtained. All obtained results provide useful information for a further development of a Sapienza Ablative Material with the aim to be competitive with other carbon-phenolic ablators.

\section{Data Available Statement}

The datasets generated during and/or analyzed during the current study are available from the corresponding author on reasonable request.

Funding Open access funding provided by Università degli Studi di Roma La Sapienza within the CRUICARE Agreement.

Open Access This article is licensed under a Creative Commons Attribution 4.0 International License, which permits use, sharing, adaptation, distribution and reproduction in any medium or format, as long as you give appropriate credit to the original author(s) and the source, provide a link to the Creative Commons licence, and indicate if changes were made. The images or other third party material in this article are included in the article's Creative Commons licence, unless indicated otherwise in a credit line to the material. If material is not included in the article's Creative Commons licence and your intended use is not permitted by statutory regulation or exceeds the permitted use, you will need to obtain permission directly from the copyright holder. To view a copy of this licence, visit http://creativecommons.org/licenses/by/4.0/.

\section{References}

1. Martin, A., Boyd, I.D.: Non-Darcian behavior of pyrolysis gas in a thermal protection system. J. Thermophys. Heat Transf. 24, 60-68 (2010). https://doi.org/10.2514/1.44103

2. Bianchi, D., Nasuti, F., Martelli, E.: Navier-Stokes Simulations of Hypersonic Flows with Coupled Graphite Ablation. J. Spacecr. Rockets. 47, 554-562 (2010). https://doi.org/10.2514/1.47995

3. Steltzner, A.D., Martin, A.M.S., Rivellini, T.P., Chen, A.: AAS 13-236 Mars Science Laboratory Entry, Descent and Landing System Overview, IEEEAC (2008)

4. Riccio, A., Raimondo, F., Sellitto, A., Carandente, V., Scigliano, R., Tescione, D.: Optimum design of ablative thermal protection systems for atmospheric entry vehicles. Appl. Therm. Eng. 119, 541-552 (2017). https://doi.org/10.1016/j.applthermaleng.2017.03.053

5. Glass, D.E.: Ceramic Matrix Composite ( CMC ) Thermal Protection Systems ( TPS ) and Hot Structures for Hypersonic Vehicles. Seminar. 2682, 1-36 (2008). https://doi.org/10.2514/6.2008-2682

6. Bertin, J.J., Cummings, R.M.: Fifty years of hypersonics: Where we've been, where we're going. Prog. Aerosp. Sci. 39, 511-536 (2003). https://doi.org/10.1016/S0376-0421(03)00079-4 
7. Natali, M., Kenny, J.M., Torre, L.: Science and technology of polymeric ablative materials for thermal protection systems and propulsion devices: a review. Prog. Mater. Sci. 84, 192-275 (2016). https://doi. org/10.1016/j.pmatsci.2016.08.003

8. Laub B., Venkatapathy, E.: Thermal Protection System Technology and Facility Needs for Demanding Future Planetary Missions. In A. Wilson, editor, International Workshop on Planetary Probe Atmospheric Entry and Descent Trajectory Analysis and Science. ESA SP-544 (2003)

9. Wernitz, R., Eichhorn, Ch., Marynowski, Th., Herdrich, G.: Plasma Wind Tunnel Investigation of European Ablators in Nitrogen/Methane Using Emission Spectroscopy. J SPECTROSC 2013, 1-9 (2013). https://doi.org/10.1155/2013/764321

10. Helber, B., Turchi, A., Scoggins, J.B., Hubin, A., Magin, T.E.: Experimental investigation of ablation and pyrolysis processes of carbon-phenolic ablators in atmospheric entry plasmas. Int. J. Heat Mass Transf. 100, 810-824 (2016)

11. Scotti, S.J.: Current Technology for Thermal Protection Systems. (1992)

12. Tadini, P., Grange, N., Chetehouna, K., Gascoin, N., Senave, S., Reynaud, I.: Thermal degradation analysis of innovative PEKK-based carbon composites for high-temperature aeronautical components. Aerosp. Sci. Technol. 65, 106-116 (2017). https://doi.org/10.1016/j.ast.2017.02.011

13. L. Vignoles, Analytical modeling of the steady state ablation of a 3D C / C composite. 51, 2614-2627 (2008). https://doi.org/10.1016/j.ijheatmasstransfer.2008.01.008

14. Paglia, L., Tirillò, J., Marra, F., Bartuli, C., Simone, A., Valente, T., Pulci, G.: Carbon-phenolic ablative materials for re-entry space vehicles: Plasma wind tunnel test and finite element modeling. Mater. Des. 90, 1170-1180 (2016). https://doi.org/10.1016/j.matdes.2015.11.066

15. Paglia, L., Genova, V., Marra, F., Bracciale, M.P., Bartuli, C., Valente, T., Pulci, G.: Manufacturing, thermochemical characterization and ablative performance evaluation of carbon-phenolic ablative material with nano-A12O3 addition. Polym. Degrad. Stab. 169, 108979 (2019). https://doi.org/10. 1016/j.polymdegradstab.2019.108979

16. Pulci, G., Tirillò, J., Marra, F., Fossati, F., Bartuli, C., Valente, T.: Carbon-phenolic ablative materials for re-entry space vehicles: Manufacturing and properties. Compos. Part A Appl. Sci. Manuf. 41, 1483-1490 (2010). https://doi.org/10.1016/j.compositesa.2010.06.010

17. Yue Zou, Z., Qin, Y., Tian, Q., Xiong Huang, Z., Han Zhao, Z.: The influence of zirconia fibre on ablative composite materials. Plast. Rubber Compos. 48, 185-190 (2019). https://doi.org/10.1080/14658011. 2019.1585099

18. Pulci, G., Paglia, L., Genova, V., Bartuli, C., Valente, T. Marra, F.: Low density ablative materials modified by nanoparticles addition: Manufacturing and characterization. Compos. Part A Appl. Sci. Manuf. 109, (2018). https://doi.org/10.1016/j.compositesa.2018.03.025

19. Reynier, P.: Survey of convective blockage for planetary entries. Acta Astronaut. 83, 175-195 (2013). https://doi.org/10.1016/j.actaastro.2012.06.016

20. Scoggins, J.B., Rabinovitch, J., Barros-fernandez, B., Martin, A., Lachaud, J., Jaffe, R.L., Mansour, N.N., Blanquart, G., Magin, T.E.: Thermodynamic properties of carbon - phenolic gas mixtures. Aerosp. Sci. Technol. 66, 177-192 (2017). https://doi.org/10.1016/j.ast.2017.02.025

21. Wright, M., Cozmuta, I., Laub, B., Chen, Y.K., Wilcoxson, W.H.: Defining Ablative Thermal Protection System Margins for Planetary Entry Vehicles, 42Nd. 1-27 (2011). https://doi.org/10.2514/6. 2011-3757

22. Weng, H., Martin, A.: Numerical Investigation of Pyrolysis Gas Blowing Pattern and Thermal Response using Orthotropic Charring Ablative Material, 11th AIAA/ASME Jt. Thermophys. Heat Transf. Conf. 1-13 (2014). https://doi.org/10.2514/6.2014-2121

23. Marra, F., Pulci, G., Tirillo, J., Bartuli, C., Valente, T.: Numerical Simulation of Oxy-Acetylene Testing Procedure of Ablative Materials for Re-Entry Space Vehicles. Proc. Inst. Mech. Eng. Part L J. Mater. Des. Appl. 225, 32-40 (2011). https://doi.org/10.1177/14644207JMDA335

24. Tran, H.K.: Development of Lightweight Ceramic Ablators and Arc Jet Test Results. Technical Memorandum TM-108798, NASA Ames Research Center. (1994)

25. Tran, H.K., Johnson, C., Rasky, D., Hui, F., Hsu, M.T., Chen, T., Chen, Y., Paragas, D., Kobayashi, L.: Phenolic Impregnated Carbon Ablators (PICA) as Thermal Protection Systems for Discovery Missions. Technical Memorandum TM 110440, NASA Ames Research Center. (1997)

26. Dhawan, S., Vishal, M., Taploo, A.: Thermal Protection for a Re-Entry Vehicle Using Heat Ablation Process. Int. J. Sci. Res. 4, 2193-2195 (2015). https://doi.org/10.21275/v4i11.nov151618

27. Rivier, M., Lachaud, J., Congedo, P.M.: Ablative thermal protection system under uncertainties including pyrolysis gas composition. Aerosp. Sci. Technol. 84, 1059-1069 (2019). https://doi.org/10.1016/j. ast.2018.11.048

28. Auweter-Kurtz, M., Kurtz, H.L., Laure, S.: Plasma generators for re-entry simulation. J of Prop Power 12-6, 1053-1061 (1996) 
29. Ogasawara, T., Aoki, T., Hassan, M.S.A., Mizokami, Y., Watanabe, N.: Ablation behavior of SiC fiber / carbon matrix composites under simulated atmospheric reentry conditions Composites : Part A (2011). https://doi.org/10.1016/j.compositesa.2010.10.015

30. Pagan, A.S., Zuber, C., Massuti-Ballester, B., Herdrich, G., Hald, H., Fasoulas, S.: The Ablation Performance and Dynamics of the Heat Shield Material ZURAM®, 31st. Int. Symp. Sp. Technol. Sci. (2017)

31. Herdrich, G., Fertig, M., Löhle, S.: Experimental Simulation of High Enthalpy Planetary Entries. The Open Journal of Plasma Physics, ISSN 2, 150-164 (2009). https://doi.org/10.2174/1876534300902010150

32. Wang, Y., Risch, T.K., Koo, J.H., Armstrong, N., Air, E., Base, F.: Assessment of a one-dimensional finite element charring ablation material response model for phenolic-impregnated carbon ablator. Aerosp. Sci. Technol. 91, 301-309 (2019). https://doi.org/10.1016/j.ast.2019.05.039

33. Meurisse, J.B.E., Lachaud, J., Panerai, F., Tang, C., Mansour, N.N.: Multidimensional material response simulations of a full-scale tiled ablative heatshield. Aerosp. Sci. Technol. 76, 497-511 (2018). https://doi.org/10.1016/j.ast.2018.01.013

34. Paglia, L., Genova, V., Bracciale, M.P., Bartuli, C., Marra, F., Natali, M., Pulci, G.: Thermochemical characterization of polybenzimidazole with and without nano- $\mathrm{ZrO}_{2}$ for ablative materials application. JTAC (2020). https://doi.org/10.1007/s10973-020-10343-4

35. MacDonald, M., Jacobs, C., Sheikh, U.A., Laux, C.O., Morgan, R.: Measurements of Air Plasma/ Ablator Interactions in a $50 \mathrm{~kW}$ Inductively Coupled Plasma Torch. J Thermophys. Heat Transfer 46, (2015)

36. Tranchard, P., Samyn, F., Duquesne, S., Estèbe, B., Bourbigot, S.: Modelling behaviour of a carbon epoxy composite exposed to fire: Part ii-comparison with experimental results. Materials (Basel) 10, (2017). https://doi.org/10.3390/ma10050470

37. van Eekelen, T., Martin, A., Lachaud, J., Bianchi, D. :Test Case Series 3, 6th Ablation workshop. (2014)

38. Dos Santos, W.N., Mummery, P., Wallwork, A.: Thermal diffusivity of polymers by the laser flash technique. Polym. Test. 24, 628-634 (2005). https://doi.org/10.1016/j.polymertesting.2005.03.007

39. Conshohocken, W.: Standard Test Method for Thermal Diffusivity by the Flash Method 1 i. 1-11 (2012). https://doi.org/10.1520/E1461-11.2

40. Torres-Herrador, F., Turchi, A., Van Geem, K.M., Blondeau, J., Magin, T.E.: Determination of heat capacity of carbon composites with application to carbon/phenolic ablators up to high temperatures. Aerosp Sci Technol 108, 1-10 (2021). https://doi.org/10.1016/j.ast.2020.106375

41. ASTM D7264/D726M-15.: Standard Test Method for Flexural Properties of Polymer Matrix Composite Materials. Annu B ASTM Stand i 1-11 (2010) . https://doi.org/10.1520/D7264

42. Büscher, M., Esser, B., Kindler, K., List, V.: Developments at the arc heated facility LBK of DLR)., Proceedings of the 2nd European Symposium Aerothermodynamics for space vehicles, ESTEC, Noordwijk, The Netherlands. 365-362 (1995)

43. Panerai, F., Chazot, O.:, Plasmawind tunnel testing as support to the design of gas-surface interaction in-flight experiments, 17th AIAA Int. Sp. Planes Hypersonic. Syst Technol Conf 2011, (2011). https:// doi.org/10.2514/6.2011-2276

44. Gulhan, A., Esser, B., Koch, U.: Experimental Investigation of Reentry Vehicle Aerothermodynamic Problems in Arc-Heated Facilities. J Spacecraft Rockets 38, 199-206 (2001). https://doi.org/10.2514/2. 3670

45. Zuber, C., Reimer, T., Hesser, B., Gulhan, A., Herdrich, G., Biller, N.: Development of the LowDensity Phenolic-Based Fibrous Ablator ZURAM-K. J Spacecraft Rockets (2020). https://doi.org/10. 2514/1.A34754

46. Löhle, S., Hermann, T., Zander, F.: Experimental assessment of the performance of ablative heat shield materials from plasma wind tunnel testing. CEAS Sp. J. 10, 203-211 (2018). https://doi.org/10. 1007/s12567-017-0186-0

47. Milos, F.S., Chen, Y.K.: Ablation and Thermal Response Property Model Validation for Phenolic Impregnated Carbon Ablator. J Spacecraft Rockets 47, 786-805 (2010). https://doi.org/10.2514/1. 42949

48. Wong, H.-W., Peck, J., Bonomi, R.E., Assif, J., Panerai, F., Reinisch, G., Lachaud, J., Mansour, N.N.: Quantitative determination of species production from phenol-formaldehyde resin pyrolysis. Polym. Degrad. Stab. 112, 122-131 (2015). https://doi.org/10.1016/j.polymdegradstab.2014.12.020

49. Bessire, B.K., Lahankar, S.A., Minton, T.K.: Pyrolysis of Phenolic Impregnated Carbon Ablator (PICA). Appl. Mater. Interfaces 7, 1383-1395 (2015). https://doi.org/10.1021/am507816f

50. Torres-Herrador, F., Leroy, V., Helber, B., Contat-Rodrigo, L., Lachaud, J., Magin, T.: Multicomponent Pyrolysis Model for Thermogravimetric Analysis of Phenolic Ablators and Lignocellulosic Biomass. AIAA J. 58, 4081-4089 (2020). https://doi.org/10.2514/1.J059423 
51. B.O. Owiti, T. Sakai, H. Kawabata, Y. Ishida, Thermal response analysis of low density ablative materials subjected to high temperature, AIAA Scitech 2019 Forum. (2019) 1-15. https://doi.org/10. 2514/6.2019-1777

52. T. van Eekelen, J.R. Lachaud, A. Martin, I. Cozmuta, Ablation Test-Case Series \#3. Numerical Simulation of Ablative-Material Response: Code and Model Comparisons, 6th Ablation Work. (2012).

53. G. Pinaud, J.M. Bouilly, J. Barcena, S. Florez, B. Perez, W. Fisher, V. Leroy, D. Bernard, T. Massuti, G. Herdrich, others, HYDRA: Macroscopic modelling of hybrid ablative thermal protection system, 5th Int. Conf. Porous Media Its Appl. Sci. Eng. ICPM5, Kona, HI. (2014).

54. D. F. Rogers, Laminar Flow Analysis, Cambridge University Press (1992).

55. F. S. Milos, Y.-K. Chen, Comprehensive model for multicomponent ablation thermochemistry. 35th Aerospace Sciences Meeting \& Exhibit, AIAA paper (1997), DOI: https://doi.org/10.2514/6.1997-141

56. R. A. Thompson, P. A. Gnoffo, Implementation of a Blowing Boundary Condition in the LAURA Code, 46th AIAA Aerospace Sciences Meeting and Exhibit (2008), DOI: https://doi.org/10.2514/6. 2008-1243

57. Kendall R. M., Rindal R. A., An Analysis of the Chemically Reacting Boundary Layer and Charring Ablator. Part V: A General Approach to the Thermochemical Solution of Mixed EquilibriumNonequilibrium, Homogeneous or Heterogeneous Systems, NASA CR-1064, (1968).

58. Chen, Y.K., Milos, F.S.: Navier-Stokes Solutions with Finite Rate Ablation for Planetary Mission Earth Reentries. J Spacecraft Rockets 42, 961-970 (2005). https://doi.org/10.2514/1.12248

59. D. Bianchi, E. Martelli, M. Onofri, Practical Navier-Stockes Computetion of flofield with ablation products injection, Proceedings 5th European Workshop on Thermal Protection Systems and Hot Structures, (2006).

60. R. M. Kendall, E. P. Bartlett, R. A. Rindal, C. B. Moyer, An analysis of the coupled chemically reacting boundary layer and charring ablator: Part I. Technical Report CR 1060, NASA, 1968.

61. Venkatapathy, E., Laub, B., Hartman, G.J., Arnold, J.O., Wright, M.J., Allen, G.A.: Thermal protection system development, testing, and qualification for atmospheric probes and sample return missions. Examples for Saturn, Titan and Stardust-type sample return. Adv Sp Res 44, (2009) 138-150. https:// doi.org/10.1016/j.asr.2008.12.023

62. Wernitz, R., Eichhorn, C., Herdrich, C., Fasoulas, G.S., Löhle S., Röser, H.P.: Plasma Wind Tunnel Investigation of European Ablators in Air using Emission Spectroscopy, AIAA-2011-3761, 42nd Thermophysics Conference, Honolulu, Hawaii, USA. (2011)

63. Kubota Y, Fukuda K, Hatta H, Wernitz R, Herdrich G, Fasoulas S.: Comparison of thermal deformations of carbon fiber-reinforced phenolic matrix ablators by arc-plasma wind tunnel heating and quasi-static heating. Adv Compos Mater 24, 179-195 (2015). https://doi.org/10.1080/09243046.2014. 882539

Publisher's Note Springer Nature remains neutral with regard to jurisdictional claims in published maps and institutional affiliations. 